\title{
A REVIEW OF THE ANT GENUS RECURVIDRIS (HYM.: FORMICIDAE), A NEW NAME FOR TRIGONOGASTER FOREL.
}

\author{
BY BARRY BOLTON \\ Department of Entomology, \\ The Natural History Museum, \\ Cromwell Road, London SW7 5BD, U.K.
}

\section{INTRODUCTION}

The seven small yellow terrestrial myrmicine ant species referred to the genus Recurvidris are distributed in the Oriental and Indo-Australian regions. They range from India and Sri Lanka eastwards to Japan and southwards to Sulawesi in Indonesia. The genus remains unknown in New Guinea and Australia. None of the species is particularly common, and all existing samples have been collected from forest floors, either manually or extracted from samples of leaf litter. All species are known from the worker caste but queens remain undiscovered and males of only one species have been retrieved. The biology of the species remains a mystery.

The genus was first described over a century ago, from India, and was called Trigonogaster. Unfortunately this name is preoccupied by a pteromalid chalcid, so the new name Recurvidris is proposed here. The name is based on one of the most striking habitus characters of all workers in the genus, namely the long upward and forward-curved propodeal spines.

Information on these odd little ants has been slow to accumulate. Only one species and one subspecies have been described to the present, but these and some unidentified samples have featured in a couple of morphological studies. The species termed recurvispinosa by Kugler (1978), in his study of the myrmicine sting apparatus, is correctly referred to browni. In a later study Kugler (1986) examined the stings of some other samples; his "species 1" is proles, and "species 3" is browni. Specimens of his "species 2",

Manuscript received 28 February 1992

This paper is dedicated to Professor William L. Brown, Jr., on the occasion of his retirement. Thank you very much, Bill, for all your help and advice over the years. 
from Bali in Indonesia, are not present in MCZ collection. The species illustrated by Ettershank (1966) as recurvispinosa is correctly referred to pickburni. Larvae of kemneri have been described by Wheeler, G. C. \& Wheeler, J. (1954).

Standard measurements used in this paper, and abbreviations of museum names, are as defined for the solenopsidines in Bolton (1987).

\section{RECURVIDRIS nom. n.}

(Figs. 1-11)

Trigonogaster Forel, 1890: cviii. Type species: Trigonogaster recurvispinosus Forel, 1890: cix. [Junior homonym of Trigonogaster Guérin-Méneville, 1844: 1149 (Hym.: Pteromalidae).]

Diagnosis of worker. Monomorphic terrestrial myrmicine ants with the following combination of characters.

1. Palp formula 4, 3 .

2. Mandibles with 4-5 teeth on an oblique apical margin; dentition specialised by modification of the last tooth, which may be enlarged or shifted onto the basal margin.

3. Anterior clypeal margin lacking an isolated median seta; instead with a pair of long setae which straddle the midpoint.

4. Median portion of clypeus usually weakly bicarinate, vestigial to absent in some species; when distinct the carinae widely separated and approximately parallel.

5. Median portion of clypeus moderately broadly inserted between the frontal lobes, the clypeal width about equal to or broader than one of the frontal lobes where it passes between them. 6. Antennae 11-segmented, with a conspicuous apical club of three segments.

7. Frontal carinae and antennal scrobes absent.

8. Alitrunk long, the promesonotum high-arched in profile; mesonotum with a long slope posteriorly to the propodeum, the latter on a much lower level than the promesonotal arch.

9. Propodeal spiracles small, pinhole-like, situated approximately at midlength of sclerite and high on the side (approaching the outline of the dorsum). 


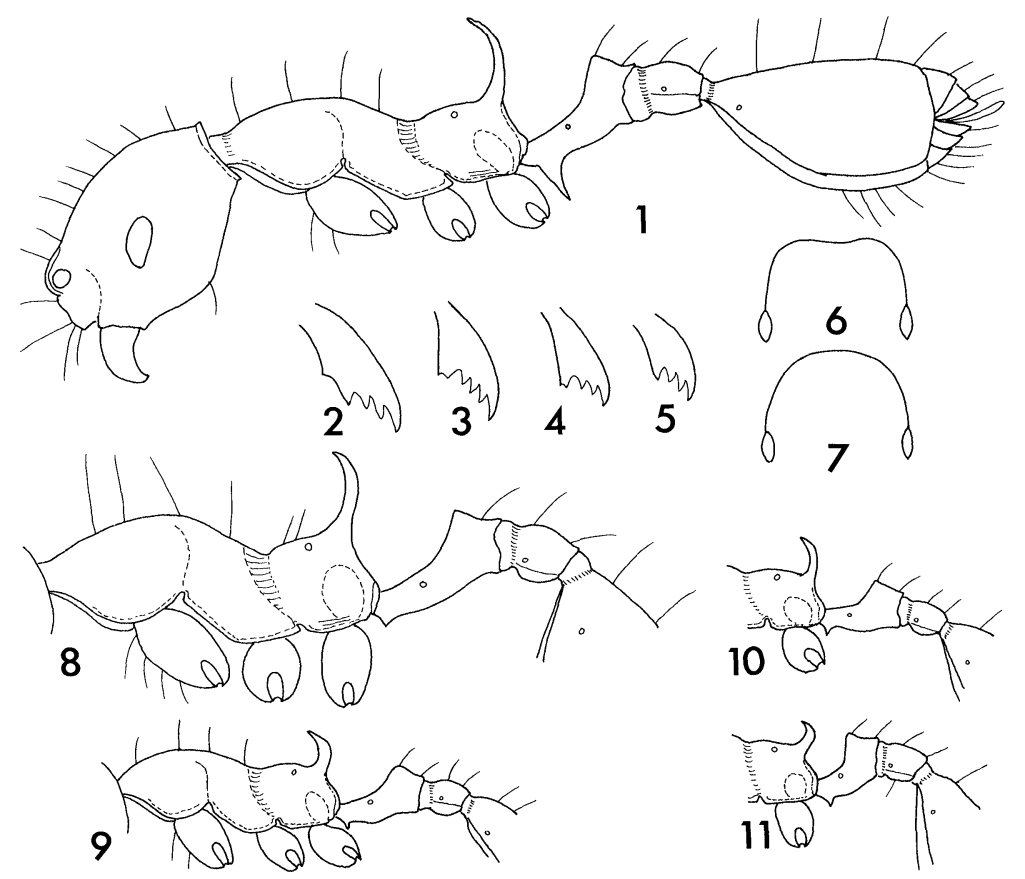

Figs. 1-11, Recurvidris workers. 1. body profile of browni. 2-5, dentition of 2 . proles, 3. browni, 4. recurvispinosa, 5. pickburni. 6-7, occipital outline of 6 . recurvispinosa, 7. hebe. 8-9, alitrunk and waist profile of 8 . proles, 9. williami. 10-11, postpetiole and waist profile of 10 . hebe, 11. recurvispinosa.

10. Bulla of metapleural gland with its dorsalmost point widely separated from the propodeal spiracle.

11. Propodeal spines present, curving upwards and forwards from their bases.

12. Metapleural lobes (= inferior propodeal plates) very small to vestigial, rounded.

13. Metasternal process absent.

14. Tibial spurs absent from middle and hind legs.

15. Posteriormost hair on mesonotal dorsum single, not paired, located on midline of sclerite.

16. Petiole pedunculate, the spiracle at about the midlength of the peduncle, the node low and weakly conical in profile. 
17. Postpetiole reduced, shallow in profile, dorsoventrally narrowed posteriorly; helcium very deep, almost or quite as deep as the body of the node.

18. First gastral segment extremely dorsoventrally compressed in profile immediately behind the postpetiole; in dorsal view attachment to the postpetiole broad.

19. First gastral segment in profile almost flat dorsally and strongly convex ventrally, the tergite strongly overlapping the sternite laterally.

20. Sting spatulate.

Queen: unknown.

Male: two poorly preserved specimens of recurvispinosa are present in MCZ; first described by Wheeler, W. M. (1927), their salient features have been summarised by Ettershank (1966).

Larva: a characterisation of the larvae of kemneri has been given by Wheeler, G. C. \& Wheeler, J. (1954).

Recurvidris has a wealth of autapomorphies in the worker caste which establish the monophyly of the genus. In short these are: the specialised dentition; the recurved propodeal spines; the single (unpaired) posteriormost hair on the mesonotal midline; the extremely specialised postpetiole with its deep helcium, reduced node, and constricted articulation with the gaster; the unique structure of the first gastral segment, as listed above.

Recurvidris is one of the many highly specialised myrmicine genera which are relatively easy to define but almost impossible to place in any currently accepted tribe. The last problem is not helped by the fact that the present tribal arrangement within the Myrmicinae is decrepit, mostly non-functional, and in need of a thorough overhaul. Unfortunately the task of putting the tribe-level classification on a good phylogenetic basis is so huge that it would most probably take more time than any one worker would be able to commit to it, under the circumstances in which taxonomy currently finds itself.

In the past Recurvidris, under its old name of Trigonogaster, has been placed either in the Pheidologetonini (Forel, 1917: 243; Emery, 1922: 210) or in the Solenopsidini (Wheeler, W. M. 1922: 663; 1927: 6). In the latest review of the genus and its supposed relatives, the pheidologetonines and solenopsidines, Ettershank (1966: 158) excluded Recurvidris from both. This left the genus in 
the tribe-level limbo that it still occupies today, and upon which I am unable to improve at the present time, except to say that the lack of an unpaired median clypeal seta appears firmly to exclude Recurvidris from the Solenopsidini (Bolton, 1987: 269).

\section{KeY TO SPECIES (workers)}

1 Apical (masticatory) margin of mandible with 4 teeth, the basal margin in addition with a small tooth which is widely separated from the basal (fourth) tooth (Fig. 2). Fourth tooth of apical margin at most only slightly larger than the third. Propodeal declivity lacking infradental lamellae or ridges linking propodeal spines to metapleural lobes (Fig. 8) .2

- Apical (masticatory) margin of mandible with 4 or 5 teeth, the basal margin unarmed. Basal tooth of apical margin (the fourth or fifth) distinctly larger than the preceding tooth, acute to bidenticulate apically (Figs. 3-5). Propodeal declivity with narrow infradental lamellae or ridges linking propodeal spines to metapleural lobes (Figs. 1, 9-11) ........................................3

2 Dorsum of propodeum with 1-2 pairs of standing hairs (Fig. 8). Clypeal carinae vestigial to absent. Larger species, HW 0.66-0.68. Head brown, much darker than the yellowish alitrunk. (Indonesia: Sulawesi) ........................................proles

- Dorsum of propodeum without standing hairs. Clypeal carinae distinct from anterior margin to about midlength of clypeus. Smaller species, HW 0.46-0.54. Colour uniformly yellow. (E. Malaysia: Sarawak; Indonesia: Java) kemneri

3 Apical (masticatory) margin of mandible with 5 teeth, the basal (fifth) tooth enlarged, larger than the third or fourth (Fig. 3).

- Apical (masticatory) margin of mandible with 4 teeth, the basal (fourth) tooth enlarged, larger than the third (Figs. 4, 5)

4 Dorsum of head finely and densely reticulate-punctate everywhere, dull and opaque. Disc of pronotum finely and densely sculptured. Subpetiolar process a short tooth (Fig. 9). Smaller species, HW 0.39. (Indonesia: Flores) ...........................williami

- Dorsum of head only with very fine superficial reticulate patterning, glossy. Disc of pronotum glassy smooth. Subpetiolar process a long spine (Fig. 1). Larger species, HW 0.47-0.54. 
(W. Malaysia: Selangor; E. Malaysia: Sarawak; Indonesia: Kalimantan) browni

5 Enlarged basal tooth of mandible acute apically (Fig. 5). (Sri Lanka) .........................................................pickburni

- Enlarged basal tooth of mandible bidenticulate apically (Fig. $4)$; may appear as abruptly truncated in worn mandibles

6 In profile the propodeal spines and petiolar peduncle relatively short and stout (Fig. 11). With the head in full-face view the occipital corners narrowly rounded (Fig. 6). Postpetiole in dorsal view 1.6-1.8 times broader than the petiole node. (Nepal, India, Burma, Hong Kong, China, Japan)... recurvispinosa

- In profile the propodeal spines and the petiolar peduncle relatively long and narrow (Fig. 10). With the head in full-face view the occipital corners broadly rounded (Fig. 7). Postpetiole in dorsal view 1.3-1.4 times broader than the petiole node. (Indonesia: Sulawesi) hebe

\section{SPECIES OF RECURVIDRIS}

The kemneri-group

(Figs. 2, 8)

1. Basal tooth on apical (masticatory) margin of mandible not enlarged, not bidenticulate apically.

2. Basal margin of mandible with a small tooth or tumulus.

3. Propodeal declivity lacking infradental lamellae or ridges that link the spines to the metapleural lobes.

4. Head relatively broad, CI range 94-106.

\section{Recurvidris kemneri comb et stat. $n$.}

Trigonogaster recurvispinosa subsp. kemneri Wheeler, G. C. \& Wheeler, J. 1954: 133. Syntype larvae: INDONESIA: Java. (Not seen, presumably in larval collection of G. C. Wheeler \& J. Wheeler.)

Note. Wheeler, G. C. \& Wheeler, J. (1954) attributed the name kemneri to W. M. Wheeler, who never in fact published any description of this taxon. They stated that the material studied was "eight larvae from Java." The MCZ collection contains a few workers with the data "Buitenzorg [=Borgor], E. I., 13.3.1921 
(N.A. Kemner)". As this old series has the correct locality and collector I presume that its workers originated in the same series as the larvae described by the Wheelers, and are therefore taken as the basis for the current identity of kemneri.

Worker. TL 2.2-2.5, HL 0.48-0.56, HW 0.46-0.54, CI 94-100, SL 0.42-0.50, SI 88-93, PW 0.28-0.34, AL 0.60-0.74 (20 measured).

Apical margin of mandible with 4 sharp teeth; basal margin with a small tooth at about its midlength. Median portion of clypeus weakly bicarinate, the carinae obvious in some specimens but less distinct in others. Head behind level of frontal lobes unsculptured. Propodeal dorsum lacking standing hairs. Propodeal declivity without infradental lamellae. Subpetiolar process a triangular tooth, slightly curved posteriorly at its apex. Colour uniform clear yellow.

Known from Java and Borneo, the populations on the two islands show some differences. At present, due in part to the poor condition of the Javan sample, I am inclined to regard both as belonging to a single species. The ants from Java are smaller than those from Borneo (at lower end of range given above) and have straight hairs on the scapes and relatively shorter propodeal spines. In Borneo material the scape hairs are all curved and the spines are longer.

The closest known relative of kemneri is proles, but the latter is larger (compare measurements), has hairs on the propodeum (Fig. 8 ), and is bicoloured.

Material examined. E. MALAYSIA: Sarawak, 4th. Div., Gn. Mulu NP (P. M. Hammond \& J. E. Marshall); Sarawak, 4th. Div. Long Pala (B. Bolton). INDONESIA: Java, Buitenzorg [=Bogor] (N. A. Kemner).

\section{Recurvidris proles sp. $\mathbf{n}$.}

(Figs. 2, 8)

Holotype worker. TL 2.8, HL 0.64, HW 0.66, CI 103, SL 0.60, SI 91, PW 0.36, AL 0.80.

Apical margin of mandible with 4 sharp teeth; basal margin with a small tooth. (In the holotype the latter is reduced to a rounded tumulus on the right mandible; in one paratype the left mandible has the basal margin tooth reduced to a tumulus; in the 
other paratype both mandibles have a sharp tooth on the basal margin.) Head broad (CI>100) and smooth, lacking sculpture. Median portion of clypeus not bicarinate. Propodeal spines slender, smoothly upcurved. Subpetiolar process a small triangular tooth. Propodeal declivity lacking infradental lamellae. Propodeal dorsum with a pair of straight standing hairs, just in front of the level of the spiracle. Body unsculptured except for some vestiges on the mesopleuron. Alitrunk and legs yellow, head and gaster brown.

Paratype workers. TL 2.8-2.9, HL 0.64-0.66, HW 0.66-0.68, CI 100-106, SL 0.60-0.62, SI 88-94, PW 0.36, AL 0.80-0.84 (2 measured). As holotype but propodeal dorsum with one or two pairs of hairs, and with variation of dentition noted above.

Holotype worker, a pencil label stating "Lore Lindu III" was the only data originally born by the holotype. I have added a second label: "SULAWESI, Lore Lindu NP, Toro, 14.vii.1983, (Moffett \& Fletcher)", the information given by Kugler (1986: 222) during his examination of the sting structure of members of this series, where it was referred to as "Trigonogaster species 1" (MCZ).

Paratypes, two workers with same data as holotype (MCZ; BMNH).

$R$. proles is the largest species yet known in the genus, and is one of the most easily recognised. The species group characters given above are shared only by kemneri and proles, but the former is a smaller species (compare measurements), clear yellow in colour, and lacking hairs on the propodeal dorsum.

\section{The recurvispinosa group}

(Figs. 1, 3-7, 9-11)

1. Basal tooth on apical (masticatory) margin of mandible enlarged and usually truncated or bidenticulate apically.

2. Basal margin of mandible unarmed.

3. Propodeal decivity with infradental lamellae that link the spines to the metapleural lobes.

4. Head relatively narrow, CI range 85-93.

The group divides neatly into two complexes as browni and williami have five mandibular teeth (Fig. 3), whereas hebe, pickburni, and recurvispinosa have only four (Figs. 4, 5). 
Recurvidris browni sp. n.

(Figs. 1, 3)

Holotype worker. TL 2.6, HL 0.58, HW 0.52, CI 90, SL 0.48, SI 92, PW 0.31, AL 0.74.

Apical margin of mandible with 5 teeth. Basal (fifth) tooth large, much larger than either tooth 3 or 4 , truncated or bidenticulate apically. Basal margin of mandible unarmed. Dorsum of head glossy, with only superficial reticular patterning which is weakest mid-dorsally. Disc of pronotum and mesonotum glassy smooth, the propodeum with fine punctulate sculpture. Recurved propodeal spines long and narrow, with a fine but distinct infradental lamella. Petiole with a very long acute anteroventral process. Standing hairs absent from propodeal dorsum. Colour yellow.

Paratype workers. TL 2.6-2.8, HL $0.54-0.58$, HW $0.49-0.54$, CI 89-93, SL 0.44-0.50, SI 90-93, PW 0.30-0.32, AL 0.74-0.76, (10 measured). As holotype.

Holotype worker, E. MALAYSIA: Sarawak, 4th. Div. G. Mulu Nat. Pk., RGS Expd., Long Pala, lowl. rainfor., forest floor, 5.x.1977 (B. Bolton) (BMNH).

Paratypes, 32 workers with same data as holotype (BMNH; MCZ).

Non-paratypic material examined. W. MALAYSIA: Selangor, Gombak, xi.1983 (M. Moffett); Gombak, 24.viii.1967 (R. Crozier). INDONESIA: Kalimantan, Batulitjin, 28.vi.-2.vii.1972 (W. L. Brown) (BMNH; MCZ). These specimens mostly fall into the range of dimensions given above, but a few are slightly smaller, down to TL 2.4, HL 0.52, HW 0.47, SL 0.43, PW 0.28, AL 0.68 (CI and SI remain in the above ranges).

This distinctive species is closest related to williami, sharing the same form of dentition. $R$. browni however is notably larger, has a very long subpetiolar process and longer, more slender propodeal spines (compare Figs. 1, 9). On the other hand williami has strong reticulate-punctate sculpture, which is lacking in browni.

Voucher specimens in MCZ indicate that this is the species which Kugler (1978: 472) referred to as recurvispinosa in his study of the myrmicine sting apparatus; it is also the "Trigonogaster species 3" of Kugler (1986: 222). 


\section{Recurvidris hebe sp. $\mathrm{n}$.}

(Figs. 7, 10)

Holotype worker. TL 1.7, HL 0.42, HW 0.38, CI 90, SL 0.32, SI 84, PW 0.22, AL 0.52.

Apical margin of mandible with 4 teeth, the basal tooth enlarged, truncated and minutely denticulate apically (as in Fig. 4); basal margin of mandible unarmed. Sides of head in full-face view rounding broadly into the occipital margin. Dorsum of head finely reticulate, the sculpture fading out mid-dorsally. Dorsal alitrunk finely superficially sculptured everywhere. Propodeal spines long, narrow and evenly upcurved. Subpetiolar process a triangular tooth. Postpetiole in dorsal view relatively narrow, only 1.3-1.4 times broader than the petiole node. Standing hairs absent from propodeum. Colour yellow.

Paratype workers. TL 1.6-1.7, HL $0.40-0.42$, HW $0.35-0.38$, CI 88-93, SL 0.32-0.34, SI 84-91, PW 0.20-0.22, AL 0.48-0.52 (10 measured). As holotype but length of subpetiolar process variable, sometimes reduced to a very short tooth.

Holotype worker, INDONESIA: Sulawesi Utara, Dumoga-Bone NP, 2m-square sample of litter, lowland rainforest, 200-400m, ii.1985, sample BB3 (P. M. Hammond) (BMNH).

Paratypes, 19 workers; 3 with same data as holotype; 8 with same data but samples BB2 (3 workers), BB12 (3 workers), BB7 (2 workers); 8 workers, Sulawesi Utara, Dumoga-Bone NP, 9-16.v.1985 (P. M. Hammond) (BMNH; MCZ).

Three species, hebe, recurvispinosa, and pickburni, share the same dental arrangement of four teeth, the basalmost of which is enlarged, combined with an unarmed basal mandibular margin (Figs. 4, 5). Of these pickburni is characterised by having an acute apex to the basal tooth, rather than the truncated bidenticulate apex seen in the other two. $R$. hebe is closest related to recurvispinosa but the two, whose distributions are not known to overlap, are separable by the characters given in the final key couplet. 


\section{Recurvidris pickburni sp. $\mathbf{n}$.}

(Fig. 5)

Holotype worker. TL 2.1, HL 0.48, HW 0.44, CI 92, SL 0.38, SI 86, PW 0.26, AL 0.58.

Apical margin of mandible with 4 teeth, the basal tooth enlarged but acutely pointed, not abruptly truncated or bidenticulate apically; basal margin of mandible unarmed. Occipital corners broadly and evenly rounded, so much so that the two sides and the occipital border of the head almost form a single even arc in fullface view. Head with superficial reticulation, fading out middorsally. Disc of pronotum smooth and shining, the propodeal dorsum with only faint superficial sculpture. Propodeal spines narrow, the subpetiolar process an elongate triangular tooth. Standing hairs absent from propodeum, where a pair of short decumbent hairs occur, above the site of the spiracle. Colour yellow.

Paratype workers. TL 1.9-2.1, HL $0.48-0.50$, HW 0.44-0.46, CI 90-92, SL 0.38-0.40, SI 85-89, PW 0.25-0.26, AL 0.57-0.60 (4 measured). As holotype.

Holotype worker, SRI LANKA: Kandy, 600-700m, 10-13.vii.1955, no. 1240 (E. O. Wilson) (MCZ).

Paratypes, 4 workers with same data as holotype but two numbered 1243, and two 1266 (MCZ; BMNH).

$R$. pickburni is characterised by its 4-dentate mandibles, on which the basal tooth is stout and acute. Some of the specimens, including the holotype, show a minute deviation in the posterior outline of the basal tooth. This may indicate that the single point of the tooth has evolved secondarily from an originally bidenticulate condition. If so the present apex of the tooth would represent the original anterior denticle and the deviation in posterior outline the last vestige of the original posterior denticle. The closest relatives of pickburni are hebe and recurvispinosa, but both of these have the basal tooth truncated to bidenticulate (compare Figs. 4, 5).

A worker of pickburni forms the basis for Ettershank's (1966: 159 , figs. 138, 139) illustration, which is attributed to recurvispinosa in his review of the genus.

This species is named in honour of a friend, Bernerd Pickburn, recently deceased. 


\section{Recurvidris recurvispinosa comb. $\mathbf{n}$.}

(Figs. 4, 6, 11)

Trigonogaster recurvispinosus Forel, 1890: cix, fig. Syntype workers, INDIA: Poona (R. C. Wroughton) (MHN) [examined].

Trigonogaster recurvispinosa: Wheeler, W. M. 1927: 5 (description of male).

Worker. TL 1.5-1.9, HL 0.40-0.48, HW 0.36-0.40, CI 86-91, SL $0.30-0.36$, SI $80-90$, PW $0.20-0.26$, AL $0.46-0.60$ (20 measured).

Apical margin of mandible with 4 teeth, the basal enlarged and bidenticulate apically; basal margin of mandible unarmed. Head in full-face view with narrowly rounded occipital corners, the sides and occipital margin not forming a single even arc. Propodeal spines stout and strong. Subpetiolar process varying from a tooth to a short somewhat curved spine. Postpetiole in dorsal view 1.6-1.8 times broader than the petiole node. Head and dorsal alitrunk usually finely reticulate-punctate to reticulate-granular. On head the sculpture usually weaker on dorsum behind the frontal lobes; stronger or better defined posteriorly and laterally. Pronotal dorsum usually more weakly sculptured than head, often the sculpture very reduced. Colour yellow to brownish yellow.

This is the most widely distributed member of the genus. It shows some sculptural variation over its range, but the differences are of degree rather than of form of sculpture. Considering the diagnostic characters that consistently separate recurvispinosa from its relatives, I feel sure that the sculptural differences represent variation within a single species, rather than indicating the presence of more than one species.

The closest relatives of recurvispinosa are pickburni and hebe, but in both of these the propodeal spines are much narrower (compare Figs. 10, 11) and the occipital margin of the head is broadly rounded (compare Figs. 6,7). Apart from these, the basal tooth of the mandible is acutely pointed in pickburni (Fig. 5), and the postpetiole in dorsal view is narrower in hebe.

Material examined. NEPAL: Kathmandu (M. G. Allen). INDIA: Dehra Dun (A. K. Mehra); Assam, Kaziranga (Wittmer \& Baroni Urbani); Kerala, Walayar Forest (J. Noyes); Tamil Nadu, Coimbatore (J. Noyes); Tamil Nadu, Suruvani (J. Noyes); Wallon (Heim). BURMA: Pegu (Bingham). HONG KONG: King's Park $(R$. 
Winney). CHINA: Back Liang (D. F. Light). JAPAN: Is. Ishigaki, Mt Omoto (M. Tanaka).

\section{Recurvidris williami sp. $\mathbf{n}$.}

(Fig. 9)

Holotype worker. TL 1.8 , HL 0.44 , HW 0.39 , CI 89 , SL 0.34 , SI 87, PW 0.23, AL 0.56 .

Apical margin of mandible with 5 teeth, the basal tooth broad and abruptly truncated apically; basal margin of mandible unarmed. Dorsum of head everywhere dull and opaque, reticulatepunctate. Dorsal alitrunk finely and densely sculptured everywhere, the pronotum and propodeum reticulate-punctate. Propodeal spines stout, the subpetiolar process small and toothlike, slightly back-curved. Standing hairs absent only on propodeal dorsum. Colour yellow.

Holotype worker. INDONESIA: Flores I., Nangagete, ca $60 \mathrm{~km}$ E. Maumere, 19.vii.1972, tropic. evgn. forest (W. L. Brown) (MCZ).

Known only from the holotype worker this very distinctive small species is closest related to browni. Within the recurvispinosa-group williami shares the same dentition as browni (Fig. 3), but has dense sculpture on the head and dorsal alitrunk, lacks a large subpetiolar process, has shorter stouter propodeal spines, and is much smaller (compare Figs. 1, 9; and measurements under the two names).

\section{SUMMARY}

A review of the small myrmicine ant genus Recurvidris (new name for Trigonogaster Forel) is presented. Seven species are recognised of which five, browni, hebe, pickburni, proles, williami, are newly described. The genus is distributed through the Oriental and Indo-Australian regions and its species are denizens of the forest floor. A modern diagnosis of Recurvidris is given and a key to its species presented, along with a synopsis of current knowledge of the genus and its included species. 


\section{ACKNOWLEDGEMENTS}

My thanks to Stefan Cover (MCZ, Cambridge) for the loan of Recurvidris material deposited there, and to Daniel Burckhardt (MHN, Geneva) for type-material of $R$. recurvispinosa.

\section{LiterATURE Cited}

BOLTON, B.

1987. A review of the Solenopsis genus-group and revision of Afrotropical Monomorium Mayr. Bulletin of the British Museum (Natural History)

EMERY, C. (Entomology) 54: 263-452.

1922. In Wytsman, P. Genera Insectorum. Hymenoptera, Fam. Formicidae, subfam. Myrmicinae. Fasc. 174C: 207-397. Bruxelles.

ETTERSHANK, G.

1966. A generic revision of the world Myrmicinae related to Solenopsis and Pheidologeton. Australian Journal of Zoology 14: 73-171.

FOREL, A.

1890. Aenictus-Typhlatta découverte de M. Wroughton. Nouveaux genres de formicides. Annales de la Société Entomologique de Belgique. Comptes-rendus 34: cii-cxiv.

1917. Cadre synoptique actuel de la faune universelle des fourmis. Bulletin de la Société Vaudoise des Sciences Naturelles 51: 229-253.

GuÉrin-MÉNEVILLE, F. E.

1844. Observations sur un insecte qui attaque les olives, dans nos départements méridionaux, et cause une diminution très-considérable dans la récolte de l'huile. Comptes Rendus Hebdomadaires des Séances de l'Académie des Sciences 19: 1147-1150.

Kugler, C.

1978. A comparative study of the myrmicine sting apparatus. Studia Entomologica (N. S.) 20: 413-548.

1986. Stings of ants of the tribe Pheidologetini. Insecta Mundi 1: 221-230.

WHEeler, G. C. \& WHEELER, J.

1954. The ant larvae of the myrmicine tribe Pheidologetini. Psyche 60 (1953): 129-147.

WHEELER, W. M.

1922. The ants of the Belgian Congo. Bulletin of the American Museum of Natural History 45: 1-1139.

1927. Chinese ants collected by Professor S. F. Light and Professor N. Gist Gee. American Museum Novitates 255: 1-12. 

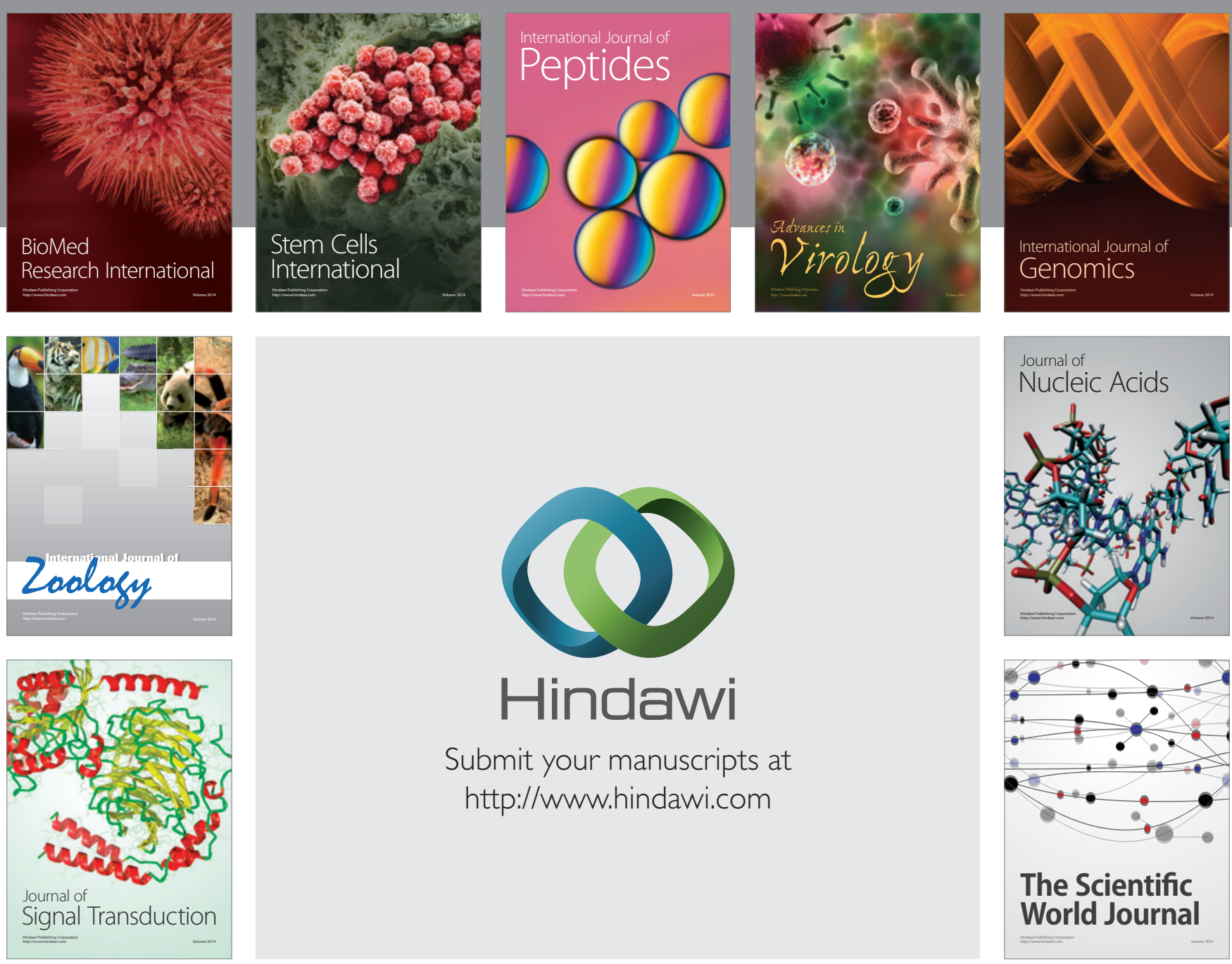

Submit your manuscripts at

http://www.hindawi.com
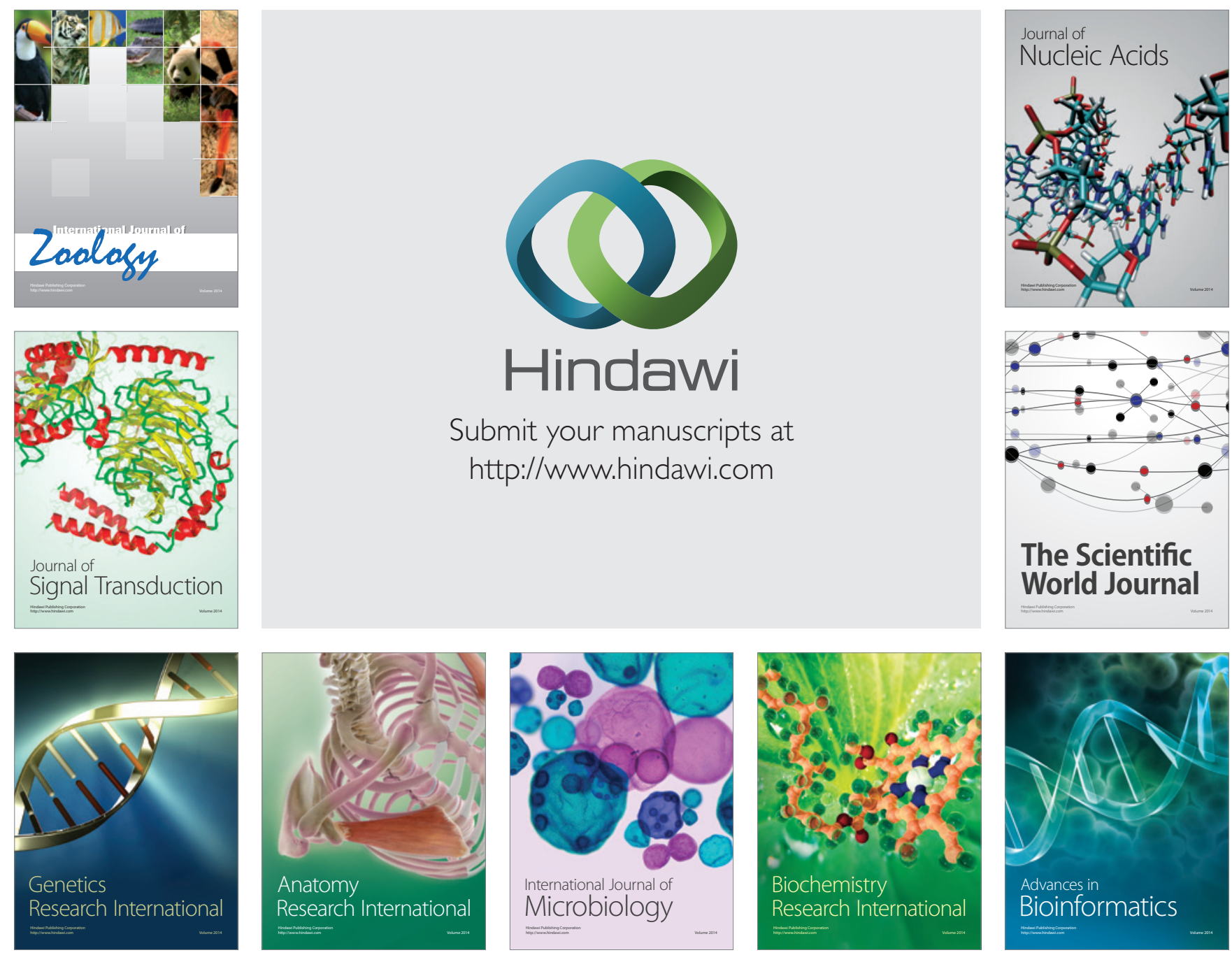

The Scientific World Journal
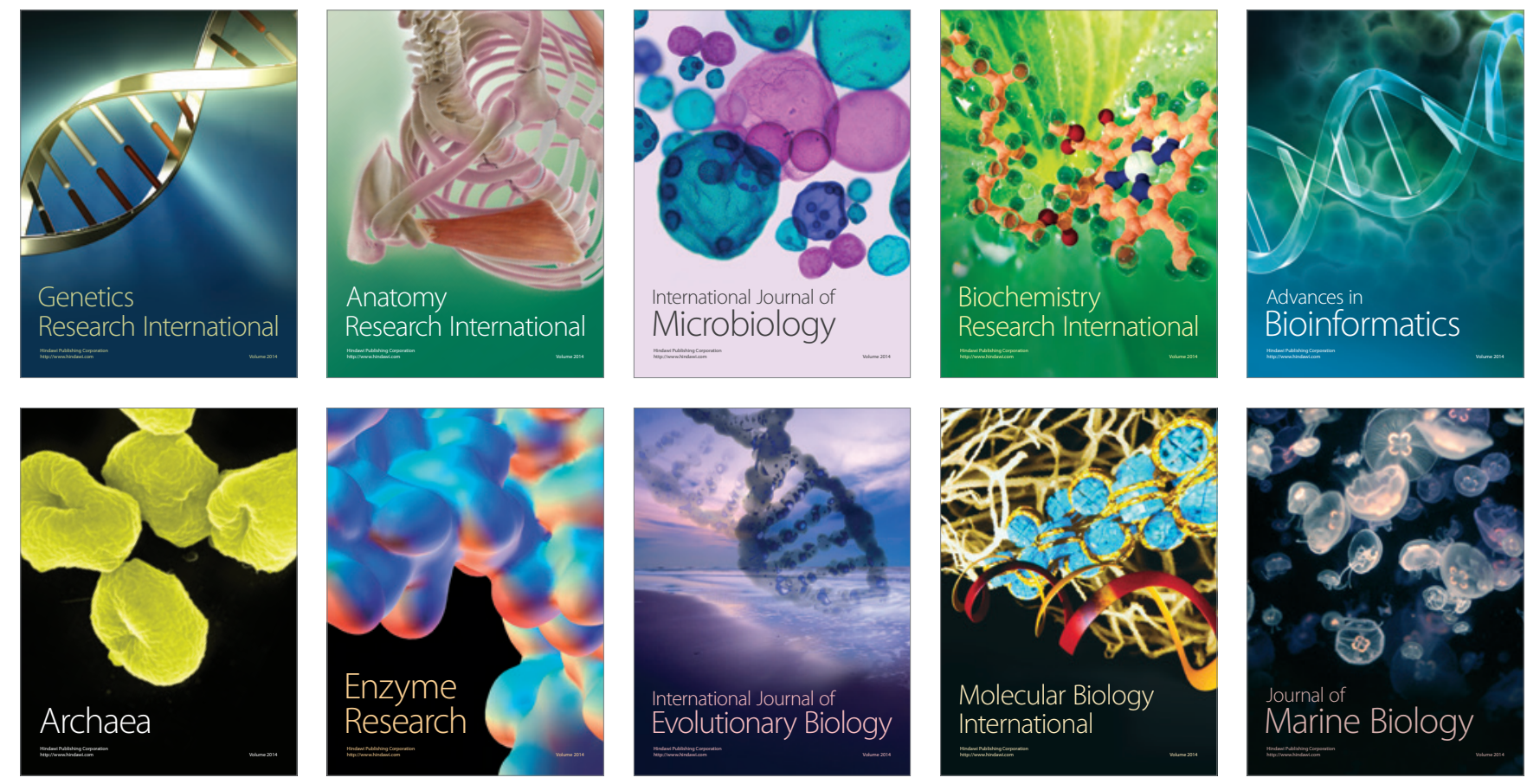